\title{
What Is Expected of a Medical Director in the Centers for Medicare and Medicaid Services Conditions of Coverage?
}

Jay B. Wish

University Hospitals Case Medical Center, Cleveland, Ohio, USA

\section{Key Words}

Medical director $\cdot$ Quality improvement $\cdot$ Interdisciplinary teams $\cdot$ Patient safety $\cdot$ Conditions of coverage $\cdot$ Measures assessment tool

\begin{abstract}
The Medicare Conditions for Coverage for dialysis facilities, effective since 2008, make the medical director responsible for all levels of quality patient care in the facility. This includes issues such as water quality, infection control, staff education, policy/procedure development and implementation, dialyzer reuse, involuntary discharges, and patient safety. Most importantly, the medical director is the leader of the team responsible for quality assessment and performance improvement, which is central to the process of continuous quality improvement in the dialysis facility and the basis for much of Medicare's evaluation of facility performance. Through the measures assessment tool, the Conditions for Coverage specify the required domains for quality improvement activities in the dialysis facility, including dialysis adequacy, nutrition, bone disease, anemia management, vascular access, medical errors, patient satisfaction, and infection control. Under the leadership of the medical director, the quality assessment and performance improvement team identifies opportunities for improvement, tests and implements interventions, collects data, interprets results, and links system change with improved outcomes.
\end{abstract}

These activities are rigorously documented and provide evidence to Medicare that the facility is acting responsibly to provide the best possible services for which it is being paid. The medical director is fairly compensated for his/her services by the facility, but must always act in the patients' best interest when evaluating policy changes directed at cost containment. The success of a medical director in shepherding positive change in a dialysis facility can be immensely satisfying as it impacts on patients other than his/her own.

Copyright $\odot 2011$ S. Karger AG, Basel

\section{Introduction}

The current Conditions for Coverage (CfC) for endstage renal disease (ESRD) facilities in the US were adopted by Medicare on April 15, 2008, and became effective on October 14, 2008 [1]. The CfC document is 116 pages long, and represents the first comprehensive change in Medicare's oversight of ESRD facilities since 1976. The provisions of the CfC are enforced by surveyors from the Department of Health of the state in which the ESRD facility resides. In addition, many states have operational requirements and/or licensing provisions for ESRD facilities that exceed those of the CfC. In their review of ESRD facilities as agents for Medicare, state surveyors employ a manual which provides guidance on the methodology for assessing compliance with the CfC [2]. 
This 189-page manual is publically accessible and provides each facility with much of the information it needs to prepare for a Medicare state survey. Even greater detail regarding the implementation of the CfC by the Medicare surveyors can be found in the ESRD Program Interpretive Guidance, a 304-page document which contains the measures assessment tool (MAT) summarizing many of the indicators which fall under the responsibility of the facility medical director and which will be discussed in further detail below [3]. The responsibilities of the ESRD facility medical director in the new CfC are dramatically increased from the previous CfC and comprehensive in their scope. 'The medical director has the responsibility of ensuring that all policies and procedures relative to patient care and safety are followed by all who treat the patient, as required by $\$ 494.150$ (c)' [2]. 'The medical director is accountable to the governing body for the quality of medical care provided to patients’ $\$ 494.150$. The CfC require that the governing body ensure all staff have appropriate orientation regarding their employment responsibilities, including medical directors. This requirement does not preclude the governing body from requiring that the medical director receive additional training deemed necessary to perform the duties of his/her position. If the medical director fails to perform at the level deemed necessary, the governing body can require a plan of correction and, should performance not improve, the governing body is directed to report the medical director to the ESRD Network Medical Advisory Board, the State Licensing Boards, State Professional Board, and any other suitable agencies or organizations. A summary of the broad categories of medical director responsibilities is shown in table 1.

\section{The Interdisciplinary Team}

Patient assessment is performed by an interdisciplinary team (IDT) which consists of, at a minimum, the patient or the patient's designee, a registered nurse, a physician treating the patient for ESRD, a social worker, and a dietitian. The IDT is responsible for providing each patient with individualized and comprehensive assessment of her or her needs. The comprehensive assessment must be used to develop the patient's treatment plan and expectations for care. The medical director is not to assume the role of the patient's personal physician or to supersede that physician's decisions. However, the medical director is responsible for overseeing and assuring that all medical staff members, whether physician or physician extender,
Table 1. Medical director responsibilities

Leading quality improvement team

Facility staff training and education

Infection control

Water quality

Dialyzer reuse

Ensuring patients' rights

Reviewing adverse events and outcomes

Developing, reviewing and implementing patient care policies and procedures

Reviewing and approving involuntary patient discharges

Reviewing clinical performance measure data

comply with the requirements to see each patient, review each patient's progress, and provide input to the IDT. The governing body of the facility is responsible for setting expectations of the medical staff for quality of care $\$ 494.180$ (c), for credentialing of medical staff, and for providing medical directors with adequate institutional authority to address underperforming physicians and physician extenders. If the medical director is unsuccessful in achieving staff compliance or managing disciplinary issues involving attending physicians and has exhausted all options, it is expected that the matter would be referred to the governing body, ESRD Network or other appropriate authorities, such as the state health department and state licensing boards.

\section{Quality Assessment and Performance Improvement}

The CfC requires that every ESRD facility develop, implement, maintain and evaluate an effective, data-driven quality assessment and performance improvement (QAPI) program with participation by the professional members of the IDT and led by the medical director (Interpretive Guidance V626). The QAPI program is designed to achieve a measurable improvement in health outcomes and a reduction in medical errors using indicators or performance measures that are tracked over time and result in actions that result in performance improvement. The QAPI activities are prioritized based on the prevalence and severity of problems and their impact on clinical outcomes and patient safety. Problems with the greatest priority would be those that pose serious health and safety threats such as unsafe water, defective clinical equipment, unsafe reprocessing of dialyzers, infection control, and insufficient number of competent staff. The 
Table 2. Patient-level indicators in the MAT

\begin{tabular}{|c|c|c|c|}
\hline Condition/standard & Measure & Target value & QAPI goal \\
\hline HD adequacy & $\begin{array}{l}\text { Duration } \\
\mathrm{Kt} / \mathrm{V}\end{array}$ & $\begin{array}{l}\text { Min. } 3 \mathrm{~h} / \mathrm{tx} \text { if } \mathrm{RKF}<2 \mathrm{ml} / \mathrm{min} \\
>1.2 \text { (on } \mathrm{HD}>3 \text { months) }\end{array}$ & Increase $\%$ patients at target \\
\hline Nutrition & $\begin{array}{l}\text { Albumin } \\
\text { Body weight }\end{array}$ & $\begin{array}{l}>4.0 \mathrm{~g} / \mathrm{dl} \text { BCG; if BCP lab normal } \\
\% \text { usual or standard weight, BMI }\end{array}$ & Increase $\%$ patients at target \\
\hline Bone disease & $\begin{array}{l}\text { Corrected Ca } \\
\text { Phosphorus } \\
\text { PTH }\end{array}$ & $\begin{array}{l}\text { Normal for lab; prefer }<10 \mathrm{mg} / \mathrm{dl} \\
3.5-5.5 \mathrm{mg} / \mathrm{dl} \\
\text { Adult: } 150-300 \mathrm{pg} / \mathrm{ml}\end{array}$ & $\begin{array}{l}\text { Increase } \% \text { patients at target } \\
\text { Increase } \% \text { patients at target } \\
\text { Increase } \% \text { patients at target }\end{array}$ \\
\hline Anemia & $\begin{array}{l}\text { Hemoglobin } \\
\text { TSAT } \\
\text { Serum ferritin }\end{array}$ & $\begin{aligned} & 10-12 \mathrm{~g} / \mathrm{dl}(\text { on ESA, on HD }>3 \text { months }) \\
> & 20 \% \text { or } \mathrm{CHr}>29 \mathrm{pg} / \text { cell } \\
> & 200 \text { (HD) and }<500 \mathrm{ng} / \mathrm{ml}\end{aligned}$ & $\begin{array}{l}\text { Increase } \% \text { with mean } 10-12 \\
\text { Evaluate if indicated } \\
\text { Evaluate if indicated }\end{array}$ \\
\hline Vascular access & $\begin{array}{l}\text { Fistula (AVF) } \\
\text { Graft (AVG) } \\
\text { Catheter } \\
\text { Thrombosis } \\
\text { Infections } \\
\text { Patency }\end{array}$ & $\begin{array}{l}\text { Preferred } \\
\text { Acceptable if AVF not possible } \\
\text { Avoid }\end{array}$ & $\begin{array}{l}>65 \% \\
<10 \% \text { for }>90 \text { days } \\
<0.25 / \text { patient-year AVF } \\
<0.50 / \text { patient-year AVG } \\
<1 \% \text { AVF; }<10 \% \text { AVG } \\
>3 \text { years AVF; }>2 \text { years AVG }\end{array}$ \\
\hline Medical errors & Reporting & Decrease frequency through prevention, early identifi & ication and root cause analysis \\
\hline Reuse & Evaluation of program & Maximize effectiveness & Decrease adverse outcomes \\
\hline $\begin{array}{l}\text { Patient QOL and } \\
\text { satisfaction }\end{array}$ & $\begin{array}{l}\text { KDQOL } \\
\text { CAHPS } \\
\text { Grievances }\end{array}$ & $\begin{array}{l}\text { Achieve and sustain scores of average or above, no de } \\
\text { Increase } \% \text { of patients satisfied with care } \\
\text { Prompt resolution of patient grievances }\end{array}$ & clines $>10$ \\
\hline Infection control & $\begin{array}{l}\text { Trends } \\
\text { Immunizations }\end{array}$ & $\begin{array}{l}\text { Minimize infections and transmission of same } \\
\text { Documentation of patient education } \\
\text { Increase } \% \text { of patients vaccinated on schedule } \\
\text { Increase } \% \text { of patients receiving flu shots } 10 / 1-3 / 31\end{array}$ & \\
\hline
\end{tabular}

$\mathrm{RKF}=$ Residual kidney function; $\mathrm{HD}=$ hemodialysis; $\mathrm{BCG}=$ bromcresol green albumin assay; $\mathrm{BCP}=$ bromcresol purple albumin assay; $\mathrm{Ca}=$ calcium; $\mathrm{PTH}=$ parathyroid hormone; TSAT = transferrin saturation; $\mathrm{ESA}=$ erythropoiesis-stimulating agent; $\mathrm{CHr}=$ reticulocyte hemoglobin content; KDQOL = Kidney Disease Quality of Life survey; CAHPS = Consumer Assessment of Health Providers and Systems survey.

QAPI team is responsible for periodically reviewing the quality indicators, educating the facility staff in QAPI objectives, reviewing the method for prioritizing QI projects, communicating with the governing body, and evaluating the effectiveness of the QAPI program. The Medicare state surveyors evaluate the data and records of QAPI activities, review the change in clinical outcomes that have resulted, and interview responsible staff (including the medical director) regarding the processes that have occurred. The QAPI program will fail if the facility has failed to recognize and prioritize major problems, failed to take action on these programs, and/or failed to develop a written plan describing QAPI scope, objectives, organization, responsibilities, participants, and procedures.

Expectations of Dialysis Medical Director

\section{The Measurement Assessment Tool}

The MAT is a comprehensive matrix of clinical performance indicators that fall under the responsibility of the medical director, are specified in the ESRD Interpretive Guidance, and provide the basis for many Medicare survey and certification activities [4]. These include water quality, dialyzer reuse, individualized and comprehensive patient assessment by the IDT, the development of a written individualized comprehensive plan of care for each patient by the IDT, and the implementation, maintenance and evaluation of an effective data-driven QAPI program. The major patient-level clinical indicators in the MAT are summarized in table 2. 


\section{Water Quality}

The medical director is responsible for the quality of dialysate water in the facility. He/she is expected to be familiar with and understand the components of the water purification system. He/she should have knowledge of the usual maintenance procedures for the water system as well as triggers for intervention. The medical director must review the monthly results of the water and bacteriology testing of the water system and the dialysis machines, and that review should be documented. As water quality is one of the components of the MAT, it is expected that the medical director's role in maintaining and improving water quality will be documented in the minutes of the QAPI meetings addressing water quality.

\section{Infection Control}

The medical director is the chief infection control officer of the dialysis facility and is expected to be involved in all infection control issues. Specifically, he/she must be familiar with the infection control program at the facility (and may be required to provide specific examples to the state surveyor), is responsible for receiving all reports related to infection control, must continuously review all surveillance reports and identify problems, must document any action taken to address infection control issues, and is ultimately responsible for the reporting of infections and adverse event clusters to the public health authorities. Infection control issues that are new to the 2008 CfC include isolation of hepatitis B virus-positive patients, contact precautions for infected skin wounds and fecal incontinence, strict hand hygiene for all patient contact, environmental cleaning and disinfection of dialysis stations, and one-way flow of supplies and medications (including the avoidance of multi-dose vials). The CfC require each dialysis facility to implement a comprehensive infection control program that includes routine serologic testing for hepatitis $B$ and $C$, immunization for hepatitis $\mathrm{B}$, influenza and pneumococcus, infection control training and education of staff and patients, and surveillance. Central venous catheter-related bacteremias are an appropriate focus of both surveillance and QAPI activities, and the medical director has a critical role in leveraging his/her knowledge and engaging potential partners when appropriate. Such partners may include infection control professionals in an affiliated health care system, the ESRD Network, public health officials, and independent consultants. The medical director must lead the in- fection control effort by example and promote a culture of patient and worker safety, continuously communicating the effort as a facility priority.

\section{Other Responsibilities}

The medical director is responsible for approving the training program for patient care dialysis technicians, for participating in the development, periodic review and approval of a patient care policies and procedures manual for the facility, and for signing off on all involuntary patient discharges and transfers. The medical director is responsible for reviewing and incorporating into the facility's quality improvement plan reports regarding quality metrics received from external agencies such as the ESRD Network and the Kidney Epidemiology and Cost Center (KECC). The latter includes information regarding the facility's performance on anemia management and dialysis adequacy, as well as standardized ratios for mortality, hospitalization and transplantation.

\section{Medical Director Compensation}

The medical director of a dialysis facility deserves to be paid at the market rate for the services he/she performs for the facility. Medicare estimates that if the medical director fulfills all of his/her responsibilities, that work would take $25 \%$ of the medical director's professional time. Medicare has estimated that the market rate for a nephrologist's services is around USD 100 per hour. If the medical director works for the facility an average of $10 \mathrm{~h}$ per week, that would compute to an annual compensation of around USD 50,000. Compensation in excess of this amount will be scrutinized by Medicare and the Office of the Inspector General as possibly inappropriate and an inducement for the referral of patients, which is illegal and may result in administrative and criminal action against both the medical director and the facility. It should be noted that time spent providing direct care to patients in a dialysis facility is not included in the medical director's compensation since it is separately reimbursed to the nephrologist through the monthly capitation rate. Educational activities that improve the medical director's clinical or administrative skills may be counted towards the compensation. It is strongly recommended that every medical director maintain a log of the time spent on their administrative activities to support the level of compensation for medical director services that is being received. 


\section{The Medical Director's Role in a Bundled Payment System}

As of January 2011, Medicare will be phasing in, over 3 years, a bundled payment system for dialysis providers that includes items that were previously separately billable such as intravenous medications, certain laboratory tests, and other services [5]. Physician payment, vascular access interventions, and oral medications that are not the equivalent of an intravenous medication administered on dialysis will not initially be included in the bundled payment. As items such as erythropoietic stimulating agents and intravenous vitamin $\mathrm{D}$ analogs shift from being a profit center to being a cost center for dialysis facilities, the medical director may be asked to accept and promote revised policies and procedures for cost containment. Since the medical director is accountable to patients and payers for high quality care, it will be vital for the medical director to use his/her best judgment in balancing cost and quality considerations. In many cases, increased efficiency and consistency through the use of standardized protocols will achieve the goals of both cost containment and improved quality, and the medical director must use the QAPI structure to continuously evaluate policy and procedure changes to assess their effects on quality outcomes.

\section{Conclusions}

The CfC have made the medical director the 'captain of the ship' for quality in the dialysis facility. The responsibilities are far-reaching and time-consuming, requiring political and administrative skills that may not be intuitive. Nonetheless, most of the nephrology community has embraced this consolidation of medical leadership as being an acknowledgment by Medicare that the nephrologist, based on knowledge, experience and clinical judgment, is the appropriate individual to advocate for quality at all levels in the dialysis facility. The blueprint for the medical director's activities is clear from the $\mathrm{CfC}$, and the reward transcends the financial compensation as the medical director improves the quality for all patients in the facility, not just his/her own.

\section{Disclosure Statement}

The author declares no conflict of interest.

\section{References}

1 Department of Health and Human Services, Centers for Medicare and Medicaid Services: 42 CFR Parts 405, 410, 413 et al. Medicare and Medicaid Programs; Conditions for Coverage for End-Stage Renal Disease Facilities; Final Rule. http://www.cms.gov/CFCs AndCoPs/downloads/ESRDfinalrule0415. pdf; accessed August 17, 2010.

2 Department of Health and Human Services, Centers for Medicare and Medicaid Services: State Operations Manual, Appendix H Guidance to Surveyors: End-Stage Renal Dis- ease Facilities (Rev. 1, 05-21-04). http://www. cms.gov/manuals/Downloads/som107ap_h_ esrd.pdf; accessed August 17, 2010.

3 Department of Health and Human Services, Centers for Medicare and Medicaid Services: End Stage Renal Disease (ESRD) Program Interpretive Guidance, version 1.1. http:// www.therenalnetwork.org/home/resources/ InterpretiveGuidelines_memo.pdf; accessed August 17, 2010

4 Department of Health and Human Services, Centers for Medicare and Medicaid Services:
Measures Assessment Tool (MAT). http:// www.therenalnetwork.org/home/resources/ CfC/QAPI_MAT.pdf; accessed August 17, 2010.

5 Department of Health and Human Services, Centers for Medicare and Medicaid Services: 42 CFR Parts 410, 413 and 414 Medicare Program; End-Stage Renal Disease Prospective Payment System; Final Rule and Proposed Rule. http://edocket.access.gpo.gov/2010/ pdf/2010-18466.pdf; accessed August 17, 2010. 